\title{
SUPPORTING INFORMATION Sustainable Hybrid Route to Renewable Methacrylic Acid via Biomass-Derived Citramalate
}

\author{
Yuxiao Wu ${ }^{1,2}$, Manish Shetty ${ }^{1}$, Kechun Zhang ${ }^{1,2}$, Paul J. Dauenhauer ${ }^{1,2^{*}}$
}

1 University of Minnesota, Department of Chemical Engineering \& Materials Science, 421 Washington Ave. SE, Minneapolis, MN, USA, 55455.

2 Center for Sustainable Polymers, Department of Chemistry, 208 Smith Hall, 207 Pleasant Street SE, Minneapolis, MN, USA, 55455.

3 School of Engineering, Westlake University, Zhejiang, Hangzhou, Xihu, 18 Shilongshan Road Cloud Town, China.

*Corresponding Authors: zhangkechun@westlake.edu.cn, hauer@umn.edu

Table of Contents

Strains and plasmids used in this study

Summary of the temperature effect on decarboxylation of citramalate to methacrylic acid Summary of the acid addition on decarboxylation of citramalate to methacrylic acid Summary of the effect of catalysts on decarboxylation of citramalate to methacrylic acid Purification process of citramalate from fermentation

${ }^{1} \mathrm{H}-\mathrm{NMR}$ of citramalic acid after purification from fermentation

List of standard compounds and IR retention time in HPLC

Sample HPLC spectra

List of standard compounds and IR retention time in HPLC

BET surface area of catalysts used in this study

References
Page

2

3

4

5

6

7

8

9

10

11

12 
Table S1. Strains and plasmids used in this study

\begin{tabular}{|c|c|c|}
\hline Name & Relevant genotype & Reference \\
\hline \multicolumn{3}{|l|}{ Strains } \\
\hline BW25113 & $r r n B_{114} \Delta \mathrm{lac}_{\mathrm{w} 16} h s d R 514 \Delta a r a B A D_{\mathrm{AH} 33} \Delta r h a B A D_{\mathrm{LD} 78}$ & $\begin{array}{l}\text { (Datsenko and } \\
\text { Wanner, 2000) }\end{array}$ \\
\hline XL10-Gold & $\begin{array}{l}\operatorname{Tet}^{\mathrm{R}} \Delta(m c r A) 183 \Delta(\text { mcrCB-hsaSMR-mrr }) 173 \\
\text { endAl supE44 thi-1 recAl }\end{array}$ & Stratagene \\
\hline $\begin{array}{l}\text { CM1 } \\
\text { (JW0071-1) }\end{array}$ & BW25113 $\triangle l e u C$ & $\begin{array}{l}\text { Keio Collection } \\
\text { (Baba et al, } \\
2006)^{2}\end{array}$ \\
\hline $\begin{array}{l}\text { CM2 } \\
\text { (JW0070-1) }\end{array}$ & BW25113 $\triangle l e u D$ & $\begin{array}{l}\text { Keio Collection } \\
\text { (Baba et al, } \\
\text { 2006) }\end{array}$ \\
\hline CM3 & BW25113 $\Delta l e u C \triangle l e u D$ & This study \\
\hline CM4 & BW25113 $\triangle l e u C \triangle a c k A$ & This study \\
\hline \multicolumn{3}{|l|}{ Plasmids } \\
\hline CMA-1 & ColE1 origin, AmpR, PLlacO1:cimA & This study \\
\hline
\end{tabular}


Table S2. Summary of the temperature effect on decarboxylation of citramalate to Methacrylic acid (MAA). The figure is given in figure 4 of the main text.

\begin{tabular}{ccccccc}
\hline Temperature & Conversion & \multicolumn{5}{c}{$\begin{array}{c}\text { Selectivity } \\
(\boldsymbol{\%})\end{array}$} \\
\cline { 3 - 7 }$\left({ }^{\circ} \mathbf{C}\right)$ & $(\boldsymbol{\%})$ & Others & Byproducts & Isomers & $\boldsymbol{\alpha}$-HIBA & MAA \\
\hline 200 & 2.5 & 0.2 & 0.6 & 54.7 & 0.0 & 44.3 \\
225 & 75.2 & 0.7 & 17.7 & 26.4 & 12.1 & 37.7 \\
250 & 95.0 & 7.7 & 19.0 & 3.1 & 24.8 & 45.6 \\
275 & 91.6 & 18.0 & 16.6 & 0.6 & 10.9 & 45.0 \\
300 & 100 & 26.1 & 10.8 & 0.4 & 17.2 & 31.7 \\
\hline
\end{tabular}


Table S3. Summary of the acid addition on decarboxylation of citramalate to Methacrylic acid (MAA). The figure is given in figure 6 of the main text.

\begin{tabular}{|c|c|c|c|c|c|c|}
\hline \multirow{2}{*}{$\begin{array}{c}\text { HCl } \\
\text { (eqv.) }\end{array}$} & \multirow{2}{*}{$\begin{array}{c}\text { Conversion } \\
\qquad(\%)\end{array}$} & \multicolumn{5}{|c|}{$\begin{array}{c}\text { Selectivity } \\
(\%)\end{array}$} \\
\hline & & Others & Byproducts & Isomers & $\alpha$-HIBA & MAA \\
\hline 0 & 87.9 & 0.4 & 62.1 & 18.2 & 0.0 & 21.1 \\
\hline 1 & 95.0 & 1.3 & 20.3 & 4.5 & 19.0 & 53.9 \\
\hline 2 & 92.9 & 17.3 & 15.8 & 4.7 & 11.7 & 44.8 \\
\hline 3 & 95.5 & 20.2 & 6.4 & 37.2 & 0.0 & 17.9 \\
\hline 6 & 83.6 & 29.4 & 3.9 & 33.8 & 0.0 & 7.0 \\
\hline
\end{tabular}


Table S4. Summary of the effect of catalysts on decarboxylation of citramalate to Methacrylic acid (MAA). The data is represented in figure 6 of the main text.

\begin{tabular}{ccccccc}
\hline Catalyst & Conversion & \multicolumn{5}{c}{$\begin{array}{c}\text { Selectivity } \\
(\boldsymbol{\%})\end{array}$} \\
\cline { 3 - 7 } & $(\boldsymbol{\%})$ & Others & Byproducts & Isomers & $\boldsymbol{\alpha}$-HIBA & MAA \\
\hline control & 95.0 & 7.7 & 19.0 & 3.1 & 24.8 & 45.6 \\
$10 \mathrm{wt} \% \mathrm{Pd} / \mathrm{C}$ & 96.4 & 4.9 & 20.3 & 4.7 & 18.5 & 54.6 \\
$5 \mathrm{wt} \% \mathrm{Ru} / \mathrm{C}$ & 95.4 & 41.2 & 19.3 & 3.0 & 9.9 & 23.8 \\
$10 \mathrm{wt} \% \mathrm{Pt} / \mathrm{C}$ & 94.7 & 70.9 & 11.4 & 3.3 & 0.0 & 0.0 \\
$\mathrm{carbon}$ & 92.3 & 8.4 & 17.4 & 1.2 & 24.8 & 45.9 \\
$\gamma-\mathrm{Al}_{2} \mathrm{O}_{3}$ & 93.6 & 4.9 & 13.9 & 3.5 & 20.7 & 63.2 \\
\hline
\end{tabular}


Table S5. Summary of the effect of catalysts on decarboxylation of citramalate to Methacrylic acid (MAA).

\begin{tabular}{ccccccc}
\hline Catalyst & Conversion & \multicolumn{5}{c}{$\begin{array}{c}\text { Selectivity } \\
(\%)\end{array}$} \\
\cline { 3 - 7 } & $(\%)$ & Others & Byproducts & Isomers & $\boldsymbol{\alpha}$-HIBA & MAA \\
\hline $2 \times \gamma-\mathrm{Al}_{2} \mathrm{O}_{3}$ & 96.0 & 1.4 & 14.8 & 4.4 & 25.0 & 62.8 \\
$\mathrm{HZSM} 5(40)^{\mathrm{a}}$ & 92.7 & 2.7 & 10.3 & 3.3 & 30.0 & 63.2 \\
$\mathrm{HZSM} 5(12)^{\mathrm{a}}$ & 91.4 & 1.9 & 10.8 & 4.8 & 30.2 & 63.1 \\
$\mathrm{HZSM} 5(300)^{\mathrm{a}}$ & 97.0 & 4.7 & 14.3 & 0.6 & 34.4 & 59.3 \\
$5 \mathrm{wt} \% \mathrm{Pd} / \mathrm{C}$ & 91.7 & 8.8 & 17.6 & 3.0 & 23.0 & 50.6 \\
$1 \mathrm{wt} \% \mathrm{Pd} / \mathrm{C}$ & 93.6 & 2.7 & 18.6 & 3.0 & 26.2 & 51.1 \\
$5 \mathrm{wt} \% \mathrm{Pd} / \mathrm{SiO} 2$ & 96.0 & 7.5 & 16.3 & 3.2 & 19.7 & 52.8 \\
$5 \mathrm{wt} \% \mathrm{Pd} / \gamma-$ & & & & & & \\
$\mathrm{Al} \mathrm{O}_{3}$ & 93.8 & 1.6 & 14.0 & 2.0 & 27.4 & 61.2 \\
$10 \mathrm{wt} \% \mathrm{Pd} / \mathrm{C}$ & & & & & & \\
$+\gamma-\mathrm{Al}{ }_{2} \mathrm{O}_{3}$ & & & & & & \\
$(1: 1)$ & 90.3 & 6.6 & 15.4 & 4.3 & 21.1 & 53.6 \\
\hline
\end{tabular}

a: The number in the brackets represent the $\mathrm{SiO}_{2} / \mathrm{Al}_{2} \mathrm{O}_{3}$ ratio. 


\section{Purification process of citramalate from fermentation}

By HPLC fraction collector: The fermentation broth was centrifuged at 9000 RMP for 10 minutes to remove e.coli cell debris and calcium carbonate. The supernatant was concentrated by rotovap with isopropanol and dry ice condensing. The solution was heated in a water bath at $70{ }^{\circ} \mathrm{C}$ under vacuum to remove water. The fraction collector was set at collecting the sample from rentention time $9.2 \mathrm{~min}-9.7$ min. After collecting samples, water was removed by using the rotovap until crystals of citramalic acid appeared. The samples were collected and dried in a vacuum oven overnight.

By extraction: The fermentation broth was centrifuged at $9000 \mathrm{RMP}$ for 10 minutes to remove e.coli cell debris and calcium carbonate. Hydrochloric acid $(\mathrm{HCl})$ was added to the supernatant to tune the $\mathrm{pH}$ of the solution to 1.5 . The $\mathrm{pH}$ value of the aqueous phase was determined with a $\mathrm{pH}$ meter. The supernatant was concentrated 3-5 times by rotovap with isopropanol and dry ice condensing. The solution was heated in a water bath at $70^{\circ} \mathrm{C}$ under vacuum to remove water. All extraction experiments were conducted in $1.0 \mathrm{~L}$ flasks at room temperature. The solvents used were trioctylamine-diluent 3:7 mixtures. The diluents used included dodecane, chloroform and ethyl acetate. It was determined that ethyl acetate was the most effective diluent when extracting citramalic acid. $200 \mathrm{~mL}$ of the mixture solvent and $500 \mathrm{~mL}$ of the carboxylic acid solution were added to a flask. The flask containing the mixture was shaken for about 6.0 $\mathrm{h}$ in a shaker bath with a vibration rate of $200 \mathrm{rpm}$ and then was left to equilibrate for 1-2 $\mathrm{h}$, during which the two phases separated. The upper layer (extractant phase) was removed, and an aqueous-phase sample was taken from the bottom layer (aqueous phase) for solute concentration analyses. $0.1 \mathrm{M}$ ammonia solution was used to extract citramalte back to the aqueous phase. This process was repeated three times, afterwhich crystals were formed. 


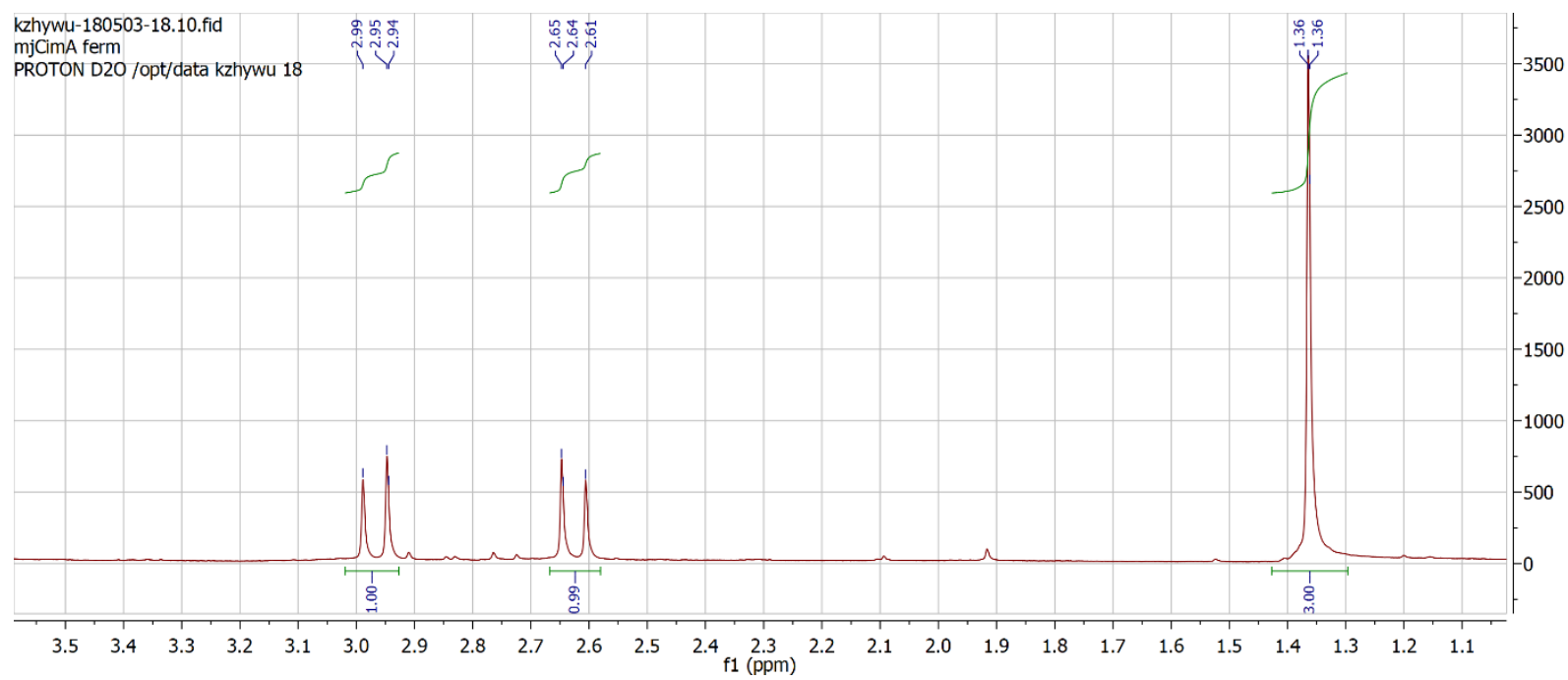

Fig. S1. ${ }^{1} \mathrm{H}-\mathrm{NMR}$ of citramalic acid after purification from fermentation. 
Table S6. List of standard compounds and IR retention time in HPLC.

\begin{tabular}{ll}
\hline Compound name & $\begin{array}{l}\text { Retention time } \\
\text { (min) }\end{array}$ \\
\hline Glucose & 8.8 \\
Citramalic acid & 9.5 \\
Pyruvic acid & 9.9 \\
Citraconic acid & 10.6 \\
2-Hydroxyisobutaric acid & 12.7 \\
Itaconic acid & 12.2 \\
Acetic acid & 14.6 \\
Mesaconic acid & 15.6 \\
Acetaldehyde & 18.0 \\
Acetone & 20.8 \\
Crotonic acid & 24.2 \\
Methacrylic acid & 22.4 \\
\hline
\end{tabular}




\section{HPLC spectra: examples}

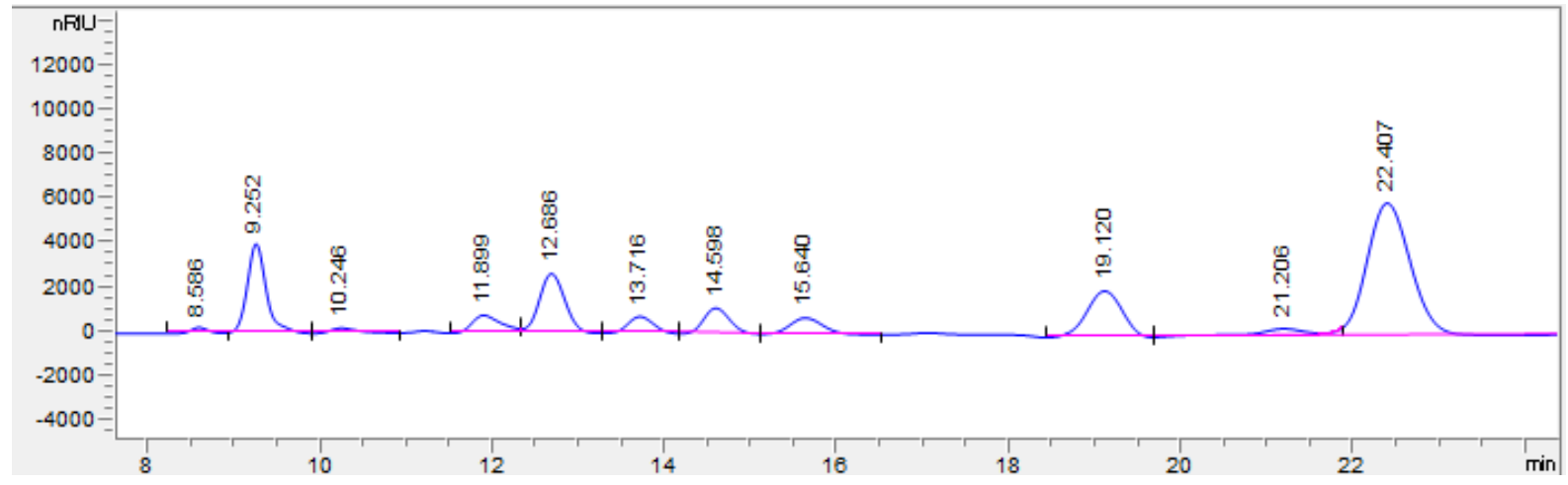

Figure S2. HPLC spectrum of citramalate after decarboxylation 
Table S7. BET surface area of catalysts used in this study

\begin{tabular}{ll}
\hline Catalyst & Surface Area $\left(\mathbf{m}^{2} / \mathbf{g}\right)$ \\
\hline $10 \mathrm{wt} \% \mathrm{Pd} / \mathrm{C}$ & 748.2 \\
$\gamma-\mathrm{Al}_{2} \mathrm{O}_{3}$ & 212.1 \\
$5 \mathrm{wt} \% \mathrm{Ru} / \mathrm{C}$ & 781.9 \\
$10 \mathrm{wt} \% \mathrm{Pt} / \mathrm{C}$ & 1344.9 \\
$5 \mathrm{wt} \% \mathrm{Pd} / \mathrm{SiO}_{2}$ & 273.3 \\
$5 \mathrm{wt} \% \mathrm{Pd} / \gamma-\mathrm{Al}_{2} \mathrm{O}_{3}$ & 120.5 \\
\hline
\end{tabular}




\section{References}

1. Datsenko, K. A. \& Wanner, B. L. One-step inactivation of chromosomal genes in Escherichia coli K-12 using PCR products. Proc. Natl. Acad. Sci. U. S. A. 97, 6640-6645 (2000).

2. Baba, T. et al. Construction of Escherichia coli K-12 in-frame, single-gene knockout mutants: The Keio collection. Mol. Syst. Biol. 2, (2006). 